\title{
STUDIES IN STEROID METABOLISM. XXVII. A COMPARISON OF THE STEROID RESPONSE TO ACTH AND CORTISONE IN NORMAL YOUNG MEN ${ }^{1}$
}

\author{
By ATTALLAH KAPPAS, 2 KONRAD DOBRINER, $\dagger$ AND T. F. GALLAGHER
}

(From the Sloan-Kettering Institute for Cancer Research, New York, N. Y.)

(Submitted for publication November 24, 1954; accepted May 25, 1955)

This study deals with the isolation and quantitative estimation of urinary ketosteroids following the administration of adrenocorticotrophic hormone $(\mathrm{ACTH})$ and cortisone acetate to two normal young men, with appropriate control studies of their endogenous steroid excretion. The study was undertaken to obtain information on several aspects of endocrine physiology. The first of these was to provide an acceptable comparison for an investigation of the influence of stress upon the young male subject as measured by the output of steroid hormone metabolites. The second was to secure basic information relating to the nature of the adrenal response and the metabolic pathways utilized when the adrenal gland was stimulated by its trophic hormone as well as when the pituitary secretion was suppressed by the administration of large doses of exogenous steroid. The third was to obtain data after intravenously administered ACTH for comparison with the several studies in which much larger amounts of this hormone were administered by the intramuscular route. The fourth was to obtain evidence from related metabolic experiments on single individuals, serving as their own controls, to test the several generalizations that have been made concerning the metabolic fate of steroid hormones. While the design of the studies and the methods employed provide information upon these topics, it should be emphasized that in certain respects the amount of hormone administered has been in the pharmacologic range and the end products studied constitute only a portion of the total metabolites.

1 This investigation was carried out under contract DA-49-007 MD-341 with the Office of the Surgeon General, Department of the Army.

2 Research Fellow of the American Cancer Society upon recommendation of the Committee on Growth of the National Research Council.

† Konrad Dobriner died March 10, 1952.

\section{EXPERIMENTAL}

The two subjects studied were hospitalized on the Metabolic Unit of the Peter Bent Brigham Hospital during both experimental periods. Both subjects were 21 years of age. The details of the studies were as follows.

Subject C21. Following a nine-day control period (Period 1) a daily intravenous infusion of $20 \mathrm{mg}$. of ACTH (Armour) dissolved in $500 \mathrm{ml}$. of 5 per cent dextrose in water was administered. These infusions continued for a total of 3 consecutive three-day periods (Periods 2, 3, and 4). The duration of each infusion was 8 hours. Except for $2.7 \mathrm{gm}$. of $\mathrm{KCl}$ per day, no other medication was given. Blood pressure and body weight remained essentially constant during the experimental period. Twenty days following the last day of ACTH administration, he was re-admitted to the Metabolic Unit for a six-day control period (Period 5). Then $500 \mathrm{mg}$. per day of cortisone acetate (Merck) was administered orally, in divided dosage, for 2 consecutive three-day periods (Periods 6 and 7). An inadvertent omission of one dose (125 mg.) of cortisone acetate on the fifth day (Period 7) was compensated by increasing the dose to $625 \mathrm{mg}$. on the sixth and last day of this experimental period. He received $2.7 \mathrm{gm}$. per day of $\mathrm{KCl}$ during the period of cortisone administration. Blood pressure and body weight did not change during this portion of the study.

Subject M21. The same lot of ACTH was administered, and essentially the same program was followed with this subject, as with subject C21. However, urines from only eight days of the ACTH administration period were studied in M21. A small weight gain was recorded at the end of this period. Blood pressure did not change. Sixteen days after the end of the ACTH experiment, he was re-admitted for the cortisone study. Details of this experiment were similar to those in the study on subject C21. Blood pressure did not change at the end of cortisone administration, but again a slight weight gain was recorded.

Control urines were pooled. Urine collected during the period of ACTH and cortisone administration were combined into consecutive three-day pools (except for the two-day ACTH pool (Period 4) in the study on subject M21). The urinary steroid conjugates were hydrolyzed by a combination of methods employing enzymatic (beef liver $\beta$-glucuronidase), mild and vigorous acid hydrolysis (see Method D [1]). The neutral 
TABLE I

Ketosteroid $(K S)^{*}$ values by Zimmermann reaction and "formaldehydogenic steroid" (FS) $\dagger$ values on various fractions of enzyme and acid hydrolyzed urine during control, cortisone and ACTH periods of C21

\begin{tabular}{|c|c|c|c|c|c|c|c|}
\hline \multirow{2}{*}{ Fraction } & \multicolumn{7}{|c|}{ Milligrams per 24 hours } \\
\hline & $\begin{array}{c}\text { Control } \\
16.9\end{array}$ & \multicolumn{3}{|c|}{ ACTH I.V. 20 mg./day } & $\begin{array}{c}\text { Control } \\
17.3\end{array}$ & \multicolumn{2}{|c|}{ Cortisone } \\
\hline $\begin{array}{l}\text { A. Enzyme-neutral KS } \\
\text { B. Acidt-neutral KS } \\
\text { C. Enzyme--water soluble ketonic KS } \\
\text { D. Enzyme-benzene soluble ketonic KS } \\
\text { E. Acid ketonic KS } \\
\text { F. Line D and E combined KS } \\
\text { G. " } \alpha \text { " from F-KS } \\
\text { H. " } \beta \text { " from F-KS } \\
\text { I. "FS", of C } \\
\text { J. "FS", of non-ketonic from C } \\
\text { K. "FS" of D }\end{array}$ & $\begin{array}{r}16.9 \\
12.9 \\
1.1 \\
13.7 \\
7.9 \\
21.6 \\
19.3 \\
1.6 \\
3.6 \\
9.7 \\
0.5\end{array}$ & $\begin{array}{r}25.8 \\
12.9 \\
3.0 \\
23.0 \\
9.1 \\
32.1 \\
27.5 \\
2.8 \\
15.1 \\
28.6 \\
8.9\end{array}$ & $\begin{array}{r}31.3 \\
17.3 \\
4.8 \\
25.6 \\
12.5 \\
38.1 \\
31.4 \\
4.0 \\
42.0 \\
22.4 \\
42.7 \\
13.3\end{array}$ & $\begin{array}{r}35.6 \\
15.5 \\
5.5 \\
27.1 \\
11.6 \\
38.7 \\
33.1 \\
4.3 \\
24.4 \\
54.6 \\
12.0\end{array}$ & $\begin{array}{r}17.3 \\
14.2 \\
1.1 \\
15.3 \\
9.8 \\
25.1 \\
22.2 \\
3.1 \\
3.4 \\
14.8 \\
2.7\end{array}$ & $\begin{array}{r}35.6 \\
11.3 \\
7.0 \\
21.1 \\
6.6 \\
27.7 \\
26.0 \\
2.2 \\
54.6 \\
78.3 \\
3.5\end{array}$ & $\begin{array}{r}37.7 \\
10.1 \\
6.3 \\
18.6 \\
6.5 \\
25.1 \\
26.5 \\
0.9 \\
61.9 \\
36.2\end{array}$ \\
\hline
\end{tabular}

* $\mathrm{KS}=$ Ketosteroid in mg. equivalents of dehydroisoandrosterone.

$\dagger \mathrm{FS}=$ Formaldehydogenic steroids in mg. equivalents of desoxycorticosterone.

$\ddagger$ Acid hydrolysis was carried out on the combined acidic fraction from which the neutral ether soluble extract was obtained and the residual urine after incubation with the enzyme followed by ether extraction.

steroid extract obtained after enzymatic hydrolysis was partitioned between benzene and water according to the method of Mason (2). The benzene soluble fraction was then combined with the neutral steroid extract from the acid hydrolysis. The combined extract was then separated into "ketonic" and "non-ketonic" fractions and the ketonic portion was further separated into " $\alpha$ " and " $\beta$ " ketosteroids (3). "Formaldehydogenic" steroids, using the method of Hollander, Di Mauro, and Pearson (4), as well as ketosteroids, by the method of Talbot, Butler, MacLachlan, and Jones (5), were measured on appropriate fractions. These values are recorded in Table I for Subject $C$ and Table II for Subject $M$. Only the " $\alpha$-ketosteroids" (line G, Tables I and II) were employed for the isolation of the individual steroids.

Separation of the ketosteroids was achieved by adsorption chromatography on silica gel and the components were identified by infrared spectrometry. The separation of urinary ketosteroid metabolites by adsorption chromatography on silica gel, although extensively used in the past in these laboratories, has not hitherto been described. The general procedure used was, in all respects, very similar to that employed for chromatography with alumina as the adsorbent except for the sequence of solvents used for elution. The ratio of adsorbent to ketosteroid (in terms of dehydroisoandrosterone as standard) was customarily 500:1. The material to be chromatographed was placed upon the previously prepared column in as small a volume as practical of a mixture of petroleum ether and approximately 0.5 per cent ethyl acetate. The column was then developed with small increments of ethyl acetate in petroleum ether. The acetates of androsterone and etiocholanolone were usually eluted with petroleum ether: ethyl acetate 93:7. Androstane-3,17-dione and etiocholane-3,17-dione were usually eluted with the same mix-

TABLE II

Ketosteroid $(K S)^{*}$ values by Zimmermann reaction and "formaldehydogenic steroid" (FS) $\dagger$ values on various fractions of enzyme and acid hydrolyzed urine during control, cortisone and ACTH periods of $M 21$

\begin{tabular}{|c|c|c|c|c|c|c|c|}
\hline \multirow{2}{*}{ Fraction } & \multicolumn{7}{|c|}{ Milligrams per 24 hours } \\
\hline & \multirow[b]{2}{*}{\begin{tabular}{r|} 
Control \\
18.0 \\
10.8 \\
1.3 \\
15.6 \\
7.6 \\
23.2 \\
23.5 \\
1.1 \\
2.8 \\
11.2 \\
1.0
\end{tabular}} & \multicolumn{3}{|c|}{ ACTH I.V. 20 mg./day } & \multirow[b]{2}{*}{\begin{tabular}{r|} 
Control \\
20.7 \\
12.0 \\
1.6 \\
16.5 \\
8.1 \\
24.6 \\
22.1 \\
0.6 \\
3.2 \\
25.7 \\
2.4
\end{tabular}} & \multicolumn{2}{|c|}{ Cortisone } \\
\hline $\begin{array}{l}\text { A. Enzyme-neutral KS } \\
\text { B. Acidł-neutral KS } \\
\text { C. Enzyme-water soluble ketonic KS } \\
\text { D. Enzyme-benzene soluble ketonic KS } \\
\text { E. Acid ketonic KS } \\
\text { F. Line D and E combined KS } \\
\text { G. " } \alpha \text { " from F-KS } \\
\text { H. " } \beta \text { " from F-KS } \\
\text { I. "FS" of C } \\
\text { J. "FS", of non-ketonic from C } \\
\text { K. "FS" of D }\end{array}$ & & \begin{tabular}{r|}
31.4 \\
13.8 \\
3.0 \\
27.1 \\
8.4 \\
35.5 \\
32.3 \\
1.2 \\
14.1 \\
33.5 \\
8.3
\end{tabular} & $\begin{array}{r}28.4 \\
18.0 \\
3.6 \\
23.2 \\
14.2 \\
27.4 \\
35.2 \\
2.4 \\
13.5 \\
37.7 \\
12.5\end{array}$ & $\begin{array}{r}28.0 \\
13.7 \\
3.8 \\
20.9 \\
11.4 \\
32.3 \\
28.9 \\
1.7 \\
17.4 \\
55.0 \\
11.2\end{array}$ & & $\begin{array}{r}35.6 \\
17.2 \\
5.9 \\
34.1 \\
7.4 \\
41.5 \\
38.7 \\
1.1 \\
44.0 \\
60.1 \\
7.4\end{array}$ & $\begin{array}{r}38.0 \\
14.8 \\
5.0 \\
25.7 \\
12.0 \\
37.7 \\
36.8 \\
1.4 \\
45.5 \\
70.5 \\
7.6\end{array}$ \\
\hline
\end{tabular}

* KS = Ketosteroid in mg. equivalents of dehydroisoandrosterone.

† FS = Formaldehydogenic steroids in mg. equivalents of desoxycorticosterone.

$\ddagger$ Acid hydrolysis was carried out on the combined acidic fraction from which the neutral ether soluble extract was obtained and the residual urine after incubation with the enzyme followed by ether extraction. 
TABLE III

Subject C21-Ketosteroid response to intravenous ACTH and oral cortisone acetate after chromatographic separation of " $\alpha$ " ketosteroids (line G, Table $I$ )

\begin{tabular}{|c|c|c|c|c|c|c|c|}
\hline \multirow[b]{2}{*}{ Compounds } & \multicolumn{7}{|c|}{ Milligrams per 24 hours } \\
\hline & Control & ACTH & ACTH & ACTH & Control & Cortisone & $\overline{\text { Cortisone }}$ \\
\hline $\begin{array}{ll}\text { Total } C_{19} & 11 \text {-oxysteroids } \\
\text { Total } C_{19} & 11 \text {-desoxysteroids }\end{array}$ & $\begin{array}{r}2.8 \\
12.2 \\
\end{array}$ & $\begin{array}{r}5.3 \\
20.4 \\
\end{array}$ & $\begin{array}{r}8.9 \\
19.8\end{array}$ & $\begin{array}{r}8.0 \\
17.9\end{array}$ & $\begin{array}{r}2.6 \\
13.5\end{array}$ & $\begin{array}{r}12.0 \\
9.5\end{array}$ & $\begin{array}{r}16.3 \\
6.4\end{array}$ \\
\hline $\begin{array}{l}3 \alpha \text {-Hydroxyetiocholane-11,17-dione } \\
3 \alpha, 11 \beta \text {-Dihydroxyetiocholane-17-one } \\
3 \alpha, 11 \beta \text {-Dihydroxyandrostane-17-one }\end{array}$ & $\frac{1.1}{1.7}$ & $\begin{array}{l}3.2 \\
\operatorname{tr} \\
2.1\end{array}$ & $\begin{array}{l}1.4 \\
2.1 \\
5.4\end{array}$ & $\begin{array}{l}1.1 \\
2.8 \\
4.1\end{array}$ & $\begin{array}{c}1.0 \\
\operatorname{tr} . \\
1.6\end{array}$ & $\begin{array}{l}9.3 \\
\operatorname{tr} . \\
2.7\end{array}$ & $\begin{array}{r}10.4 \\
1.7 \\
4.2 \\
\end{array}$ \\
\hline $\begin{array}{l}\text { Etiocholanolone } \\
\text { Androsterone } \\
\text { Ratio Androsterone : Etiocholanolone }\end{array}$ & $\begin{array}{l}6.0 \\
6.2 \\
1.0\end{array}$ & $\begin{array}{r}8.4 \\
12.0 \\
1.4\end{array}$ & $\begin{array}{r}8.4 \\
11.4 \\
1.4\end{array}$ & $\begin{array}{r}7.4 \\
10.5 \\
1.4\end{array}$ & $\begin{array}{l}5.9 \\
7.6 \\
1.3\end{array}$ & $\begin{array}{l}4.1 \\
5.4 \\
1.3\end{array}$ & $\begin{array}{l}3.6 \\
2.8 \\
0.8\end{array}$ \\
\hline
\end{tabular}

ture in the proportion $91: 9$. Androsterone is rather sharply removed from the chromatogram with $89.5: 10.5$, while a trail of this compound mixed with small amounts of etiocholanolone was usually seen when $89: 11$ was employed. Etiocholanolone was eluted with 88.5: 11.5 and continued in the eluates up to the proportion of $87.5: 12.5$. $3 \alpha, 17 \alpha$-Dihydroxypregnane-20-one was the next substance recognized and was eluted with an ethyl acetate concentration of about 20 per cent. To this stage of the chromatogram the separation is excellent and in all respects far superior to that which can be obtained by the use of alumina as an adsorbent. The separation of steroids, in fact, was comparable to that obtained by the use of partition chromatography. For the more polar compounds, however, although superior to alumina, the silica gel chromatogram is decidedly inferior to the partition chromatogram. $3 \alpha, 11 \beta$-Dihydroxyandrostane-17-one together with a very small trail of $17 \alpha$-hydroxypregnanolone is eluted with petroleum etherethyl acetate $74: 26$. $3 \alpha, 11 \beta$-Dihydroxyetiocholane-17one follows immediately after this substance and is obtained in the eluates with 28 to 32 per cent ethyl acetate. $3 \alpha$-Hydroxyetiocholane-11,17-dione is obtained immediately thereafter with 34 to 36 per cent ethyl acetate. A small amount of $3 \alpha, 11 \beta$-dihydroxyetiocholane-17-one invariably accompanies the $3 \alpha$-hydroxyetiocholane-11,17dione. Recognition of the mixtures obtained was made by comparison of the infrared spectra with those of known mixtures of the pure compounds. With careful operation of the chromatogram a separation satisfactory for the purposes of these studies is easily achieved.

\section{RESULTS}

Quantitative values for isolated ketosteroids during both experimental periods for C21, are listed in Table III and for M21, in Table IV.

\section{Subject C21}

The control values for each of the individual compounds studied were typical of those observed in healthy young males (1). The sum of the $C_{19}$ 11-desoxysteroids promptly increased, during the first period of ACTH administration. Then, despite the continued administration of ACTH, these compounds remained at essentially constant, though increased levels. Both etiocholanolone and androsterone were augmented, the latter somewhat more than the former. The increase in levels of $\mathrm{C}_{19}$ 11-oxygenated steroids was relatively of greater magnitude than that of the $\mathrm{C}_{19} 11$ desoxy compounds. This appears to be part of

TABLE IV

Subject M21-Ketosteroid response to intravenous ACTH and oral cortisone acetate after chromatographic separation of " $\alpha$ " ketosteroids (line G, Table II)

\begin{tabular}{|c|c|c|c|c|c|c|c|}
\hline \multirow[b]{2}{*}{ Compounds } & \multicolumn{7}{|c|}{ Milligrams per 24 hours } \\
\hline & Control & ACTH & ACTH & ACTH & Control & Cortisone & $\overline{\text { Cortisone }}$ \\
\hline $\begin{array}{l}\text { Total } C_{19} 11 \text {-oxysteroids } \\
\text { Total } C_{19} 11 \text {-desoxysteroids }\end{array}$ & $\begin{array}{r}2.8 \\
14.7\end{array}$ & $\begin{array}{r}8.4 \\
16.8\end{array}$ & $\begin{array}{l}11.1 \\
19.1\end{array}$ & $\begin{aligned} 8.1 \\
15.0\end{aligned}$ & $\begin{array}{r}3.7 \\
12.2\end{array}$ & $\begin{array}{r}18.6 \\
5.7\end{array}$ & $\begin{array}{r}15.3 \\
4.5\end{array}$ \\
\hline $\begin{array}{l}3 \alpha \text {-Hydroxyetiocholane-11,17-dione } \\
3 \alpha, 11 \beta \text {-Dihydroxyetiocholane-17-one } \\
3 \alpha, 11 \beta \text {-Dihydroxyandrostane-17-one }\end{array}$ & $\begin{array}{l}0.8 \\
0.4 \\
1.6\end{array}$ & $\begin{array}{l}3.1 \\
1.6 \\
3.7\end{array}$ & $\begin{array}{l}2.0 \\
4.8 \\
4.3\end{array}$ & $\begin{array}{l}2.0 \\
3.1 \\
3.0\end{array}$ & $\begin{array}{l}1.5 \\
0.6 \\
1.6\end{array}$ & $\begin{array}{r}12.7 \\
4.3 \\
1.6\end{array}$ & $\begin{array}{l}9.3 \\
2.3 \\
3.7\end{array}$ \\
\hline $\begin{array}{l}\text { Etiocholanolone } \\
\text { Androsterone } \\
\text { Ratio Androsterone : Etiocholanolone }\end{array}$ & $\begin{array}{l}7.6 \\
7.1 \\
0.9\end{array}$ & $\begin{array}{l}9.2 \\
7.6 \\
0.8\end{array}$ & $\begin{array}{r}10.9 \\
8.2 \\
0.8\end{array}$ & $\begin{array}{l}8.2 \\
6.8 \\
0.8\end{array}$ & $\begin{array}{l}6.3 \\
5.9 \\
0.9\end{array}$ & $\begin{array}{l}3.2 \\
2.5 \\
0.8\end{array}$ & $\begin{array}{l}2.7 \\
1.8 \\
0.7\end{array}$ \\
\hline
\end{tabular}


the normal characteristic pattern of adrenal response to ACTH (6). All components of this group of steroids, $3 \alpha$-hydroxyetiocholane-11,17dione, $3 \alpha, 11 \beta$-dihydroxyandrostane-17-one, and $3 \alpha, 11 \beta$-dihydroxyetiocholane-17-one shared initially in this increase, but during the later periods, the $\mathrm{C}_{10}$ 11-hydroxylated compounds predominated.

Steroid levels during the second control period were, as expected (7), essentially the same as during the first control. During cortisone administration, the $\mathrm{C}_{19}$ 11-desoxysteroids decreased in stepwise fashion, with etiocholanolone decreasing somewhat less than androsterone. As expected, levels of $\mathrm{C}_{19}$ 11-oxygenated steroids increased markedly with $3 \alpha$-hydroxyetiocholane-11, 17 -dione predominant. Small increases in $3 \alpha, 11 \beta$ dihydroxyetiocholane-17-one, and still smaller but distinct increases of $3 \alpha, 11 \beta$-dihydroxyandrostane17-one were found.

\section{Subject $M 21$}

Essentially similar metabolic results were observed in this subject. Under ACTH stimulation, levels of both 11-oxygenated and 11-desoxysteroids increased; the former, as expected, to a relatively greater extent. The increase in 11-desoxysteroids in this subject, was not as pronounced, nor as sustained as that in C21 and androsterone excretion was not measurably increased. The qualitative and quantitative pattern of $\mathrm{C}_{19}$ 11-oxygenated steroids was essentially similar to that observed in C21. Both etiocholanolone and androsterone decreased during cortisone administration. The increase in $\mathrm{C}_{19}$ 11-oxygenated steroids during cortisone administration was similar but not as pronounced as that observed in C21.

\section{DISCUSSION}

The consistent rise in output of 11-desoxy-17ketosteroids following the administration of ACTH to these and other (6) normal men was the most striking, though perhaps not unexpected, alteration in urinary ketosteroids observed. Although the two compounds, androsterone and etiocholanolone, represent the major metabolites of testosterone in man (8-10), the fact that they are consistently present in the urine of normal women (8), are identified in the urine of castrate males and females (11), and are excreted in large amounts in frank adrenal disease (12) indicates the existence of an adrenocortical precursor as well. While the absolute amounts of these two substances increased, the ratio of one to the other throughout the interval of stimulation by ACTH remained essentially unaltered (Tables III and IV). This relatively constant ratio was maintained during the period of cortisone administration with the exception of the last period in C21. This finding indicates that exogenous cortisone equally suppressed the production of the precursors of both metabolites. A simple and not unreasonable interpretation would be that the maintenance of a constant ratio during cortisone administration reflected suppression of a single precursor of both compounds. It is likely that this precursor was of adrenal origin, although depression of some testicular or pituitary hormone by the large dose of cortisone cannot be excluded. Since both androstane and etiocholane isomers were increased during ACTH administration it would be reasonable to assume that a $C_{19}$ steroid such as testosterone, $\Delta^{4}$-androstene-3,17-dione or dehydroisoandrosterone was secreted by the adrenal gland. The magnitude of the increase or decrease of the 11-desoxy metabolites is consistent with this view, since each of these potential precursors is converted to both urinary 17 -ketosteroids. The amount of hormone secreted (or suppressed) would approximate twice the increment (or decrement) found as metabolites in the urine (10) on the presumption that testosterone was the precursor. The conversion of $\mathrm{C}_{21} 17$-hydroxy precursors, such as $17 \alpha$-hydroxyprogesterone or Reichstein's "Substance S" to 17-ketosteroids is an inefficient biochemical process as evidenced by the small yield of $\mathrm{C}_{19}$ 17-ketosteroids $(13,14)$; the same is true for cortisone, exemplified in the present studies, as well as in others in which both isotopic and unlabelled precursors were employed (15-17). It seems logical, therefore, to defer consideration of a $\mathrm{C}_{21}$ steroid as a potential precursor and to focus attention upon more proximate $C_{10}$ steroids which could normally be present in the internal secretions from the adrenal gland and would be increased under intense stimulation by ACTH.

The choice of a single compound from the more likely $\mathrm{C}_{19}$ precursors mentioned is difficult but 
there is indirect evidence that points to a plausible selection. It is clear that in certain conditions such as adrenal hyperplasia of the virilizing type and in less frank manifestations of adrenal hypersecretion such as excessive hirsutism in women (18, 19) the adrenal gland can produce a physiologically active androgen. This is apparent not only from the overt manifestations seen in the several clinical states but is evident from the finding of elevated quantities of the metabolites of androgens (e.g., androsterone and etiocholanolone) in the urine. Of the three compounds under discussion, testosterone and $\Delta^{4}$-androstene-3,17-dione are the more effective in this respect. Moreover, while these two compounds can be readily metabolized to androsterone and etiocholanolone by man, they are not transformed to dehydroisoandrosterone (9, $20,21)$. Since the " $\beta$ " ketosteroid fractions from the urine of these two subjects showed only minor increases during ACTH administration, and since the excretion of dehydroisoandrosterone can be so greatly increased in abnormal adrenal hyperactivity (12), it would seem unlikely that dehydroisoandrosterone was, under physiologic circumstances, the major adrenal precursor of these two metabolites. As between testosterone and $\Delta^{4}$-androstene-3,17-dione, the evidence favors the latter since this compound has been isolated from beef adrenal extracts by von Euw and Reichstein (22) and evidence for its presence in cow adrenal perfusates has been adduced by Bloch, Dorfman, and Pincus (23). Very recently Bloch, Benirschke, and Dorfman (24) have obtained evidence for the presence of this compound in a human fetal adrenal and the adrenal of a newborn male pseudohermaphrodite. At present there is insufficient evidence available on the adrenal hormones in man to make a definitive statement about the chemical nature of the androgen which serves as the precursor of the metabolites androsterone and etiocholanolone. It is clearly necessary to study the 11-desoxysteroids from the human adrenal and we have initiated studies of this problem. As a working hypothesis, however, the suggestion can be advanced that either $\Delta^{4}$-androstene-3,17dione or testosterone would account well for the findings demonstrated in this investigation.

Following the administration of cortisone the urinary $\mathrm{C}_{19}$ 11-oxygenated ketosteroids have been studied in detail (15) and the results in subject
C21 and M21 confirm the general conclusions drawn from these previous data. In particular, it is evident that $3 \alpha, 11 \beta$-dihydroxyandrostane-17one is a metabolite, though in small amount, of cortisone, and presumably hydrocortisone. It is clear from previous work that the $11-$ keto and $11 \beta$-hydroxy functional groups are metabolically interconvertible; the degree and direction of this oxidation-reduction may reflect a variety of factors, the significance of which remains for further clarification. Thus in the subject studied by Burstein, Savard, and Dorfman (15), the major $C_{10}$ 17 -ketosteroid metabolite of cortisone was $3 \alpha, 11 \beta-$ dihydroxyetiocholane-17-one, while in our two subjects, the major 17-ketosteroid metabolite was $3 \alpha$-hydroxyetiocholane-11,17-dione. The predominant conversion of adrenosterone to $3 \alpha, 11 \beta$-dihydroxyandrostane-17-one (25), rather than to the 11-keto analog, poses similar problems of interpretation.

Dorfman (26) has reached the tentative conclusion that $3 \alpha, 11 \beta$-dihydroxyandrostane-17-one in the urine reflects, to a considerable extent, the metabolic transformation of a $\mathrm{C}_{18}$ 11-oxygenated precursor. Thus, this metabolite could arise from a $\mathrm{C}_{21}$ adrenal hormone such as hydrocortisone by a metabolic alteration that removed the two carbon side-chain prior to any change in the $\alpha, \beta$ unsaturated ketone system in Ring A or directly from a $C_{19}$ precursor such as adrenosterone or $11 \beta$-hydroxy- $\Delta^{4}$-androstene-3,17-dione. Since the latter two products are undoubtedly secreted by the adrenal gland but do not serve the vital functions of hydrocortisone, their metabolites may reflect only indirectly the extent of the adrenal response to stress. With these possibilities in view, it may be more significant to direct attention to the individual ketosteroids rather than to consider all these metabolites as a group. A more accurate indication of "adrenal response" with respect to metabolically active steroids of the hydrocortisone type would be the urinary levels of "non-ketonic" $C_{21}$ products of hormone metabolism such as pregnane-3 $\alpha, 11 \beta, 17 \alpha, 20 \alpha, 21$-pentol and related isomers (27) since these compounds account for a higher proportion of the total metabolites than do the $\mathrm{C}_{19}$ ketosteroids.

The increase in levels of $3 \alpha, 11 \beta$-dihydroxyandrostane-17-one and $3 \alpha, 11 \beta$-dihydroxyetiocholane-17-one during the administration of $\mathrm{ACTH}$ 
approached the increase in these compounds following cortisone administration. After an initial increase, the levels of $3 \alpha$-hydroxyetiocholane11,17-dione during ACTH administration decreased steadily to control values. The concurrent increase in levels of other 11-oxygenated metabolites makes it unlikely that this represents technical error or loss. A similar response was noted in a subject treated with ACTH intramuscularly (6). The results in these subjects therefore parallel those reported earlier. A point of difference from the earlier studies of the effect of $\mathrm{ACTH}$ in young men is found in the relatively minor increase in the " $\beta$ " ketosteroids of the two subjects of the present investigation. Whereas one of the previous subjects showed an increase in " $\beta$ " ketosteroids to a level of $13 \mathrm{mg}$. per day at the peak value, no such relative or absolute change was apparent with these two men. In our experience, the alterations in the " $\beta$ " fraction may be erratic and the changes observed cannot always be correlated with physiological or biochemical processes. In general terms, however, the present study agrees well with the prior report, when consideration is given to the several methodological changes as well as the different route of $\mathrm{ACTH}$ administration. In addition it may be noted that the quality of the ACTH available for the present study was probably superior to that used in the earlier investigations.

A rough comparison of the dose-response relationships after ACTH and cortisone acetate administration can be made from these, and previous data (6). From the increase in excretion of $\mathrm{C}_{19}$ 11-oxygenated metabolites during the two experimental periods, $20 \mathrm{mg}$. of ACTH administered as in this study is approximately equal to 150 to $250 \mathrm{mg}$. of cortisone acetate orally. On the same basis $20 \mathrm{mg}$. of ACTH intravenously administered produced about the same response as $100 \mathrm{mg}$. of ACTH administered by the intramuscular route. Quantitative relationships of this nature are approximations, however, since the limitations of these comparisons are evident. Alterations in the rate of absorption of administered hormones from the intramuscular depot or the gastrointestinal tract, variations in the degree of hormonal alteration and the unknown influences of biologic variations in experimental subjects may seriously influence not only quantitative relation- ships, but also qualitative patterns of metabolism as well.

\section{SUMMARY}

The qualitative and quantitative pattern of ketosteroid response has been studied in two normal young men treated experimentally with large doses of oral cortisone acetate and intravenous ACTH. Conclusions have been drawn concerning the metabolic pathways utilized when large doses of adrenal hormones are provided from exogenous, as compared with endogenous sources. In the latter situation the ketosteroid response indicates the existence of a $C_{19}$ 11-desoxy substance of adrenal origin. This hormonal substance, we conclude from a consideration of available data may represent adrenocortical production of testosterone or a chemically closely related compound and the metabolites may thus be a measure of the primary adrenal androgen.

\section{ACKNOWLEDGMENT}

We should like to extend our deep appreciation to Dr. George W. Thorn, Physician-in-Chief, Peter Bent Brigham Hospital, for permitting us participation in these studies.

The authors wish to express their appreciation to the large group of devoted Research Assistants and Technicians who made much of the work possible. The routine chemical and chromatographic separations were carried out by a group under the supervision of Madeleine Stokem and Ruth Jandorek. The colorimetric analyses were under the supervision of Denise O'Hara. The infrared spectrometry was under the supervision of Friederike Herling.

\section{REFERENCES}

1. Dobriner, K., Studies in steroid metabolism. XIX. The $\alpha$-ketosteroid excretion pattern in normal males. J. Clin. Invest., 1953, 32, 940.

2. Mason, H. L., Isolation of adrenal cortical hormones from urine; 17-hydroxycorticosterone and 17-hydroxy-11-dehydrocorticosterone. J. Biol. Chem., 1950, 182, 131.

3. Dobriner, K., Lieberman, S., and Rhoads, C. P., Studies in steroid metabolism. I. Methods for the isolation and quantitative estimation of neutral steroids present in human urine. J. Biol. Chem., 1948, 172, 241.

4. Hollander, V. P., Di Mauro, S., and Pearson, O. H., A diffusion method for the estimation of formaldehydogenic steroid. Endocrinology, 1951, 49, 617.

5. Talbot, N. B., Butler, A. M., MacLachlan, E. A., and Jones, R. N., Definition and elimination of 
certain errors in the hydrolysis, extraction, and spectrochemical assay of $\alpha$ - and $\beta$-neutral urinary 17-ketosteroids. J. Biol. Chem., 1940, 136, 365.

6. Dobriner, K., Studies in steroid metabolism. XXII. The adrenal response to $\mathrm{ACTH}$ in young and old men. J. Clin. Invest., 1954, 33, 222.

7. Dobriner, K., Studies in steroid metabolism. XX. The reproducibility of the urinary steroid pattern in humans. J. Clin. Invest., 1953, 32, 950.

8. Dobriner, K., Adrenal function and steroid excretion in disease in Symposium on Steroids in Experimental and Clinical Practice, White, A., Ed., Philadelphia, The Blakiston Co., 1951, p. 130.

9. Fukushima, D. K., Dobriner, K., and Gallagher, T. F., Studies with testosterone-d in normal men. J. Biol. Chem., 1954, 206, 845.

10. Fukushima, D. K., Bradlow, H. L., Dobriner, K., and Gallagher, T. F., The fate of testosterone infused intravenously in man. J. Biol. Chem., 1954, 206, 863.

11. Dobriner, K., and Lieberman, S., The metabolism of steroid hormones in humans in A Symposium on Steroid Hormones, Gordon, E. S., Ed., Madison, University of Wisconsin Press, 1950, p. 46.

12. Mason, H. L., Urinary steroids in adrenal disease and the metabolism of adrenal hormones. Recent Progress in Hormone Research, 1948, III, 103.

13. Fukushima, D. K., Dobriner, K., and Gallagher, T. F., Metabolic studies with deuterium steroid hormones. Federation Proc., 1951, 10, 185.

14. Gallagher, T. F., Bradlow, H. 'L., Fukushima, D. K., Beer, C. T., Kritchevsky, T. H., Stokem, M., Eidinoff, M. L., Hellman, L., and Dobriner, K., Studies of the metabolites of isotopic steroid hormones in man. Recent Progress in Hormone Research, 1954, IX, 411.

15. Burstein, S., Savard, K., and Dorfman, R. I., The in vivo metabolism of cortisone. Endocrinology, 1953, 52, 448.

16. Burstein, S., Savard, K., and Dorfman, R. I., The in vivo metabolism of 21-desoxycortisone. Endocrinology, 1953, 53, 267.
17. Burstein, S., Savard, K., and Dorfman, R. I., The in vivo metabolism of hydrocortisone. Endocrinology, 1953, 53, 88.

18. Kappas, A., Pearson, O. H., West, C. D., and Gallagher, T. F., Steroid isolation studies in female hirsutism: evidence for adrenocortical dysfunction. J. Clin. Endocrinol. \& Metab., 1954, 14, 777.

19. Van de Wiele, R., Jailer, J. W., Gold, J. J., and Lieberman, S., Attempt at classification of types of hirsutism in women by chromatographic analysis of the urinary 17-ketosteroids. J. Clin. Endocrinol. \& Metab., 1954, 14, 776.

20. Dorfman, R. I., Neutral steroid hormone metabolites. Recent Progress in Hormone Research, 1954, IX, 5.

21. Dorfman, R. I., Wise, J. E., and Shipley, R. A., Metabolism of the steroid hormones: Metabolism of $\Delta^{4}$-androstenedione-3,17, androstanedione-3,17, and androstanediol-3 $(\alpha), 17(\alpha)$, in a hypogonadal man. Endocrinology, 1950, 46, 127.

22. von Euw, J., and Reichstein, T., Uber Bestandteile der Nebennierenrinde und verwandte Stoffe. 17 $\beta$-Oxy-progesteron. Helvet. chim. acta, 1941, 24, 879.

23. Bloch, E., Dorfman, R. I., and Pincus, G., Presence of 17-ketosteroids in adrenal perfusates. Proc. Soc. Exper. Biol. \& Med., 1954, 85, 106.

24. Bloch, E., Benirschke, K., and Dorfman, R. I., The presence of $\Delta^{4}$-androstene-3,17-dione in prenatal and postnatal human adrenal glands. J. Clin. Endocrinol. \& Metab., 1955, 15, 379.

25. Savard, K., Burstein, S., Rosenkrantz, H., and Dorfman, R. I., The metabolism of adrenosterone in vivo. J. Biol. Chem., 1953, 202, 717.

26. Dorfman, R. I., in Conference on Adrenal Cortex, New York, 1953, Josiah Macy, Jr. Foundation, 1954, p. 27 et seq.

27. Fukushima, D. K., Leeds, N. S., Bradlow, H. L., Kritchevsky, T. H., Stokem, M. B., and Gallagher, T. F., The characterization of four new metabolites of adrenocortical hormones. J. Biol. Chem., 1955, 212, 449. 